\title{
REPORT OF A CASE OF PROLONGED ANURIA WITH FEW SYMPTOMS *
}

\author{
F. E. CLOUGH, M.D., F.A.C.S. \\ LEAD, S. D.
}

Mamie R., 7 years old. Premature at $6 \frac{1}{2}$ months, raised in an incubator and fed on malted milk. Teething was normal. She walked at 13 months, but was always a tiny baby. She was never sick during childhood, but was always delicate.

On March 3, 1914, she was taken with an attack of scarlet fever, so mild that it would have been overlooked, but for the fact that another more marked case appeared in the same family. All during the attack she passed but little urine, an average of $1 \frac{1}{2}$ ounces daily. On March 23 she came under my care. Physical examination at that time was negative; there was no edema nor symptoms of any description except the scanty urine. Mentally she was very bright, and continued so throughout the time reported on. The child was very thin and it was possible to palpate the entire abdomen thoroughly.

The following table represents the actual amount of urine passed over a prolonged period:

\begin{tabular}{|c|c|c|c|}
\hline \multicolumn{4}{|r|}{ Ounces } \\
\hline \multirow{11}{*}{ Date } & $\ldots 1 \frac{1 / 2}{2}$ & April & 22. \\
\hline & $29 \ldots \ldots$ & April & 24. \\
\hline & $31 \ldots \ldots \ldots \ldots \ldots \ldots, \quad 21 / 2$ & April & $\ldots 3$ \\
\hline & $\ldots \ldots \ldots 30$ & April & $\ldots 1$ \\
\hline & $\begin{array}{ll}\ldots \ldots & 3 \\
\cdots & 18 / 4\end{array}$ & $\begin{array}{l}\text { April } \\
\text { April }\end{array}$ & $\begin{array}{ll}\cdots & 3 \\
\cdots & 4\end{array}$ \\
\hline & …... & May & $\begin{array}{ll}. . & 4 \\
. & 11 / 2\end{array}$ \\
\hline & $\ldots 4$ & May & 3 . \\
\hline & …. 2 & May & .. 3 \\
\hline & $\begin{array}{ll}\cdots & 2 \\
\ldots & 13 / 4\end{array}$ & May & \\
\hline & .. $2^{1 / 2}$ & May & \\
\hline & $\cdots 3^{1 / 2}$ & $\underset{* \mathrm{P}}{\mathrm{May}}$ & $9 \ldots$ \\
\hline
\end{tabular}

From this time on the amount increased very rapidly and by the end of the following week had reached normal. On only one examination were any casts found, and then two granulars appeared. No albumin was ever detected.

This was an extremely interesting case, because the anuria seemed to have no influence on the patient's condition. At only one time did she have a convulsion and then it was not very severe. The parents of this child were very intelligent, and I am positive they did not overlook the least amount of urine passed.

When the amount on April 3 jumped to 30 ounces, we were satisfied that she had a retention, but we are of the opinion now that subsequent events showed this not to be the case. All kinds of treatment were tried: the saltfree diet, the Fischer hypertonic salt treatment, and the use of thyroid, diuretics, hot packs, etc., the only demonstrable results being no change for the worse.

The little girl was in perfect health soon after these data were compiled, and has remained so ever since. Repeated examinations of the urine in the last two years have failed to find anything pathologic.

\footnotetext{
* Submitted for publication, March 21, 1916.
} 